\title{
Kecemasan, Usia, Paritas dan Nyeri Persalinan Kala I Aktif
}

\author{
Anxiety, Age, Parity and Labor Pain \\ Phase I Active
}

\author{
Yoga Tri Wijayanti ${ }^{1 凶}$, Sumiyati $^{1}$, Prasetyowati ${ }^{1}$ \\ ${ }^{1}$ Prodi Kebidanan Metro, Politeknik Kesehatan Tanjung Karang, Indonesia \\ ${ }^{\square}$ Coresponding author: yogatriwijayanti@poltekkes-tjk.ac.id
}

\begin{abstract}
Kata kunci:
Kecemasan;

Nyeri persalinan;

Usia;

Paritas.

Abstrak

Latar belakang: Nyeri persalinan merupakan kombinasi nyeri fisik akibat kontraksi miometrium disertai regangan segmen bawah rahim yang menyatu dengan kondisi psikologis ibu selama persalinan. Nyeri persalinan yang tidak diatasi menyebabkan partus lama dan asfiksia pada janin. Tujuan: Tujuan penelitian untuk mengetahui faktor yang berhubungan dengan nyeri persalinan. Metode: Rancangan penelitian menggunakan studi cross sectional. Sampel berjumlah 32 responden dan diambil dengan teknik purposive sampling. Variabel independen meliputi kecemasan, usia dan paritas, sedangkan variabel dependen nyeri persalinan. Pengumpulan data menggunakan alat kuesioner, Zung Self-Rating Anxiety Scales (ZSAC) untuk mengukur kecemasan dan lembar observasi Numeric Rating Scale (NRS) (skala 010) untuk nyeri persalinan. Analisis bivariat menggunakan uji chi square. Hasil: Hasil penelitian menunjukkan terdapat $43,75 \%$ ibu bersalin merasakan kecemasan menghadapi persalinan. Studi memperoleh hasil ada hubungan kecemasan dengan nyeri persalinan kala I ( $p=0,017$; POR 7,5 CI 95\%: 1,3-43,7). Simpulan: Kecemasan pada ibu bersalin meningkatkan persepsi nyeri persalinan kala I. Perlu upaya penurunan atau menghilangkan kecemasan pada ibu bersalin dengan diberikan dukungan oleh keluarga atau Bidan dan pemahaman cara merespon nyeri.
\end{abstract}

Keyword:

Age;

Parity;

Anxiety;

Labor pain.

\begin{abstract}
s
Background: Labor pain is a combination of physical pain due to myometrial contraction accompanied by stretch of the lower uterine segment that integrates with the psychological condition of the mother during labor. Untreated labor pain causes prolonged labor and asphyxia in the fetus. Purpose: The purpose of this study was to determine factors associated with labor pain. Methods: The study design used a cross sectional study. The sample consisted of 32 respondents and was taken by purposive sampling technique. The independent variables include anxiety, age and parity, while the dependent variable is labor pain. Data collection using a questionnaire tool, Zung Self-Rating Anxiety Scales (ZSAC) to measure anxiety and observation sheet Numeric Rating Scale (NRS) (scale 0-10) for labor pain. Bivariate analysis using chi square test. Results: The results showed that $43.75 \%$ of mothers felt anxiety facing labor. The study found an association of anxiety with first stage labor pain ( $p=0.017$; CI 95\%: 1,3-43,7). Conclusion: Anxiety in labor increases the perception of labor pain in the first stage. It is necessary to reduce or eliminate anxiety in labor by giving support from the family or midwife and understanding how to respond to pain.
\end{abstract}

Copyright (C) 2019 Jurnal Kesehatan Metro Sai Wawai. All rights reserved. 


\section{Pendahuluan}

Persalinan merupakan pengeluaran hasil konsepsi dari dalam rahim melalui jalan lahir. Proses persalinan diawali dengan adanya kontraksi rahim yang menimbulkan dilatasi serta penipisan servik serta iskemia uterus yang memunculkan adanya rasa nyeri (Bandiyah, 2009). Nyeri persalinan merupakan kombinasi nyeri fisik akibat kontraksi miometrium disertai regangan segmen bawah rahim yang menyatu dengan kondisi psikologis ibu selama persalinan (Bobak, Jensen, \& Lowdermilk, 2012). Nyeri persalinan dan rasa sakit yang berlebihan akan menimbulkan rasa cemas, takut dan tegang yang memicu produksi hormon prostaglandin sehingga timbul stress (Judha, 2012).

Nyeri yang dirasakan pada ibu dapat menimbulkan psikologi ibu terganggu (stress) yang menyebabkan pelepasan hormon katekolamin dan steroid, sehingga dapat menyebabkan ketegangan otot polos dan vasokonstriksi pembuluh darah. Proses tersebut menimbulkan terjadinya penurunan kontraksi uterus, penurunan sirkulasi uteroplasenta, pengurangan aliran darah dan oksigen ke uterus, penurunan sirkulasi uteroplasenta, pengurangan aliran darah dan oksigen ke uterus serta timbulnya iskemia uterus yang menimbulkan bertambahnya jumlah impuls nyeri (Sumarah, Widyastuti, \& Wiyati, 2012). Peningkatkan nyeri selama melahirkan juga dapat dipicu oleh kecemasan yang tidak teratasi. Sebaliknya nyeri selama melahirkan juga menimbulkan kecemasan, sehingga antara stres, kecemasan, ketakutan dan nyeri merupakan siklus yang berkesinambungan. Sementara pasien yang mengalami nyeri empat kali lebih cemas jika di-bandingkan pasien yang tidak mengalami nyeri (Baesdo, 2008).

Hasil penelitian sebelumnya determinan non-medis paling dominan yang mendorong ibu bersalin sectio caesaria adalah ketakutan ibu karena rasa sakit pada persalinan sebesar 96,5\% (Indrayani \& Djami, 2016). Penelitian terdahulu tentang faktor resiko dan penanganan nyeri persalinan) di Mojokerto jawa Timur mengkaji hubungan antara usia,suku, pendidikan, paritas dan status pekerjaan. Adapun hasilnya menunjukkan bahwa usia, dan suku ibu bersalin berhubungan dengan nyeri persalinan kala 1 fase aktif, sedangkan pekerjaan dan paritas tidak berhubungan dengan nyeri persalinan pada kala I fase aktif (Syalfina, 2017). Hasil Penelitian Lain di Gorontalo tahun 2014-2015 tentang hubungan antara umur, paritas dan pendampingan suami dengan intensitas nyeri persalinan kala I Fase aktif menyebutkan bahwa usia melahirkan di atas 35 tahun, paritas pertama dan kurang mendapatkan dukungan suami dalam persalinan berhubungan dengan kejadian nyeri persalinan di Gorontalo (Adam dan Umboh, 2015). Adapun perbedaan penelitian ini dibandingkan dengan kedua penelitian terdahulu dengan tema terkait adalah adanya variabel lainnya selain usia dan paritas yang diteliti yaitu kecemasan ibu terhadap nyeri persalinan kala I di Trimurjo Lampung Tengah. Sedangkan, untuk variabel umur penelitian ini mengkategorikan kelompok umur tidak beresiko $<35$ tahun dan umur beresiko $>35$ tahun. Hal ini berbeda dengan kategorisasi usia pada penelitian Syalfina (2017) yang membedakan usia menjadi 2 kategori, yaitu $<20$ tahun dan $>35$ tahun serta antara 20-35 tahun.

Hasil studi pendahuluan pada bulan Mei-Juni 2018 di PMB Wilayah trimurjo Lampung Tengah. Data studi pendahuluan yang dilakukan pada 5 orang ibu yang pernah bersalin di PMB Sulistyoningsih di Wilayah Trimurjo mengatakan 3 dari 5 ibu merasakan nyeri hebat dalam persalinannya. Tujuan penelitian ini untuk mengidentifikasi usia, paritas dan kecemasan terhadap respon nyeri persalinan kala I fase aktif.

\section{Metode}

Penelitian ini merupakan penelitian kuantitatif dengan pendekatan cross sectional. Populasi dalam penelitian ini adalah seluruh ibu bersalinan kala 1 fase aktif yang bersalin di Bidan Ekasanti, AMd.Keb, dan Sulistiorahayu S.ST. Berdasarkan perhitungan didapatkan jumlah sampel minimal yang dibutuhkan adalah 29 , kemudian ditambah $10 \%$ untuk menghindari missing data sehingga jumlah sampel seluruhnya adalah 32. Teknik pengambilan sampel pada penelitian ini menggunakan purposive sampling, yaitu teknik pengambilan sampel berdasarkan pada suatu pertimbangan tertentu yang dibuat 
oleh peneliti sendiri (Notoatmodjo, 2016). Sampel yang digunakan adalah Ibu bersalin normal di wilayah Trimurjo (Bidan Ekasanti dan Sulistiorahayu) selama periode bulan Agustus- September 2018. Variabel independent dalam penelitian ini adalah usia, paritas dan kecemasan. Variabel dependent dalam penelitian ini adalah respon nyeri persalinan.

Pengumpulan data dilakukan dengan metode wawancara dan observasi. Instrumen penelitian menggunakan kuesioner dengan cara ukur angket yang digunakan untuk memperoleh data usia, paritas dan pengukuran tingkat kecemasan. Tingkat kecemasan diukur menggunakan Zung Self-Rating Anxiety Scales (ZSAC) (Kaplan \& Saddock, 1998). Sedangkan, intensitas atau tingkat nyeri dilakukan dengan menggunakan lembar observasi Numeric Rating Scale (NRS) dengan skala 0-10 (Potter \& Perry, 2005). Adapun kategorisasi nyeri dibedakan menjadi nyeri hebat dengan score NRS $>5$ dan nyeri ringan dengan sore NRS $\leq 5$. Data hasil penelitian dilakukan uji statistik yang menggunakan uji chi square. Uji ini digunakan untuk melihat hubungan usia, paritas dan kecemasan dengan respon nyeri pada ibu bersalin. Penelitian dilakukan dengan mempertimbangkan etik penelitian setelah melalui proses pemberian izin penelitian oleh Politeknik Kesehatan Tanjung Karang, Praktek Mandiri Bidan, dan informed consent dari oleh responden.

\section{Hasil}

\section{Gambaran responden}

Tabel 1 menunjukkan dari 32 orang responden gambaran karakteristik responden yang dominan adalah usia reproduktif 20-35 tahun (93,3\%), tingkat pendidikan SMA $(90,6 \%)$, pekerjaan ibu rumah tangga $(90,6 \%)$. Sedangkan, variabel tingkat kecemasan pasien separoh lebih responden tidak cemas $(56,3 \%)$ dan ibu bersalin yang merasakan nyeri hebat terdapat $62,5 \%$.

\section{Hasil analisis bivariat}

Hasil analisis bivariat dengan uji chi square pada tabel 2 diperoleh hasil ada hubungan yang bermakna antara kecemasan ibu dengan nyeri persalinan kala 1 ( $p=0,017$; POR 7,5 CI 95\% 1,3 -43,7), tidak ada hubungan antara umur ibu dengan nyeri persalinan kala I $(p=0,26)$ dan tidak ada hubungan antara paritas dengan nyeri persalinan kala I $(p=0,706)$.

\section{Tabel 1.}

Distribusi Karakteristik Responden

\begin{tabular}{lcc}
\hline \multicolumn{1}{c}{ Variabel } & Frekuensi $(\mathbf{n}=\mathbf{3 2})$ & Presentase \\
\hline Usia & 30 & \\
$\quad 20-35$ tahun & 2 & $93,3 \%$ \\
$\quad<20$ tahun dan $>35$ tahun & 2 & $6,2 \%$ \\
Pendidikan & 29 & $6,25 \%$ \\
$\quad$ Dasar (SD, SMP) & 1 & $90,6 \%$ \\
$\quad$ Menengah (SMA) & & $3,12 \%$ \\
$\quad$ Perguruan Tinggi & 29 & \\
Pekerjaan & 2 & $90,6 \%$ \\
$\quad$ Ibu Rumah Tangga & 1 & $6,25 \%$ \\
$\quad$ Wiraswata & 18 & $3,12 \%$ \\
$\quad$ Guru & 14 & $56,3 \%$ \\
Tingkat Kecemasan ibu bersalin & & $43,7 \%$ \\
$\quad$ Tidak cemas & 12 & $37,5 \%$ \\
$\quad$ Cemas & 30 & $62,5 \%$ \\
$\quad$ Tingkat Nyeri Persalinan & & \\
$\quad$ Nyeri Ringan & & \\
\hline
\end{tabular}


Tabel 2.

Distribusi frekuensi hubungan umur, paritas dan kecemasan terhadap nyeri persalinan kala I

\begin{tabular}{|c|c|c|c|c|c|c|c|c|}
\hline \multirow[b]{2}{*}{ Variabel } & \multicolumn{4}{|c|}{ Nyeri Persalinan Kala I } & \multicolumn{2}{|c|}{ Jumlah } & \multirow[t]{2}{*}{$\overline{P-V a l u e}$} & \multirow{2}{*}{$\begin{array}{c}\text { POR } \\
95 \% \text { CI }\end{array}$} \\
\hline & Nyeri Hebat & $\%$ & Nyeri ringan & $\%$ & $\begin{array}{l}N=3 \\
2\end{array}$ & $\%$ & & \\
\hline \multicolumn{9}{|l|}{ Umur } \\
\hline$\geq 35$ tahun & 2 & 100 & 0 & 0 & 2 & 100 & \multirow{2}{*}{0,26} & 1,67 \\
\hline$<35$ tahun & 18 & 60 & 12 & 40 & 30 & 100 & & $(0,2-2,2)$ \\
\hline \multicolumn{9}{|l|}{ Paritas } \\
\hline Primipara & 12 & 60 & 8 & 40 & 20 & 100 & \multirow{2}{*}{0,71} & 0,75 \\
\hline Multipara & 8 & $\begin{array}{c}66 \\
7\end{array}$ & 4 & 33,3 & 12 & 100 & & $(0,17-3,35)$ \\
\hline \multicolumn{9}{|l|}{ Kecemasan } \\
\hline Cemas & 12 & $\begin{array}{c}85 \\
7\end{array}$ & 2 & 14,3 & 14 & 100 & \multirow[b]{2}{*}{0,017} & 7,5 \\
\hline Tidak Cemas & 8 & $\begin{array}{c}74 \\
4\end{array}$ & 10 & 55,6 & 18 & 100 & & $(1,3-43,7)$ \\
\hline
\end{tabular}

\section{Pembahasan}

Faktor psikologis, seperti rasa cemas menjadi salah satu faktor peningkatan nyeri persalinan. Hasil penelitian ini menunjukkan variabel tingkat kecemasan pasien separoh lebih responden tidak cemas $(56,3 \%)$ dan ibu bersalin yang merasakan nyeri hebat terdapat $62,5 \%$. Terdapat hubungan yang bermakna antara kecemasan ibu dengan nyeri persalinan kala 1 ( $p=0.017$; POR 7,5; 95\% CI 1,3-43,7).

Cemas sebagai perasaan was-was, khawatir, atau tidak nyaman seakan-akan terjadi sesuatu yang dirasakan sebagai suatu ancaman (Keliat, 2011). Umumnya kecemasan akan timbul pada pengalaman baru yang menegangkan, terutama pada ibu yang mengalami persalinan diantaranya karena rasa nyeri yang dialami. Rasa nyeri dalam persalinan sebagai salah satu nyeri yang paling intensif yang pernah dialami ibu (Indrayani, 2013). Sensasi nyeri yang dialami ibu bersalin berasal dari sinyal nyeri yang timbul saat otot rahim berkontraksi dengan tujuan untuk mendorong bayi yang ada di dalam rahim keluar (Sondakh, 2013).

Efek kecemasan terhadap nyeri berpola seperti spiral yang ujungnya membesar. Semakin majunya proses persalinan, perasaan ibu akan semakin cepat cemas dan rasa cemas tersebut menyebabkan rasa nyeri yang semakin intens, demikian pula sebaliknya (Sariati, 2016). Ibu bersalin yang mengalami kecemasan tinggi atau stress dapat mengalami persalinan lama, kontraksi tidak adekuat. Stress psikologis memiliki efek fisik kuat pada saat persalinan. Hormon seperti adrenalin, berinteraksi dengan reseptor beta didalam otot uterus dan menghambat kontraksi dan memperlambat persalinan (Chapman, 2006; Wildan \& Purwaningrum, 2013).

Seorang ibu bersalin yang mengalami stress, takut atau terkejut, sistem simpatis dan parasimatis mudah terpicu. Kecemasan yang berlebihan dapat meningkatkan kadar katekolamin dalam darah yang berakibat meningkatnya aliran darah menuju pelvik dan meningkatkan ketegangan otot di sekitar pelvik. Tubuh merespon ketegangan otot tersebut dengan penyempitan dan menghambat aliran darah serta oksigen sehingga berdampak pada kerja otot rahim. Otot-otot segmen bawah rahim yang harusnya bekerja melemas dan membuka menjadi kaku sehingga bayi tidak dapat turun ke jalan lahir, sehingga menimbukan nyeri hebat yang dirasakan oleh ibu bersalin (Yuliatun, 2008). Wanita hamil yang sering merasa khawatir tentang rasa nyeri yang akan mereka alami saat proses persalinan akan menentukan bagaiaman mereka akan bereaksi untuk mengatasi nyeri tersebut. Ketegangan emosi akibat rasa cemas akan memperberat persepsi nyeri selama persalinan.

Ibu bersalin pada penelitian ini dari 14 orang ibu yang merasakan kecemasan saat persalinan, 12 diantaranya $(85,7 \%)$ menggalami nyeri hebat selama persalinan kala I. Hasil analisis Prevalence Odds ratio (POR) menunjukkan ibu bersalin yang mengalami kecemasan meningkatkan risiko 7,5 kali terjadinya nyeri persalinan kala I (OR 7,5 CI 95\% 1,3 -43,7). Penelitian ini sesuai dengan penelitian 
Agustina, Hartati \& Sumarni (2016) di kota Pekalongan Jawa Tengah yang menunjukkan ada hubungan yang signifikan antara kecemasan dengan tingkat nyeri ibu bersalin kala I di Pekalongan $(p=0,000)$ dengan kekuatan hubungan sedang (Spearman's rho 0,568). Untuk itu, perlunya mengurangi dan mengendalikan tingkat kecemasan ibu bersalin perlu mendapatkan bimbingan dan dukungan dari keluarga atau Bidan.

Hasil lain penelitian ini memperlihatkan bahwa usia tidak ada hubungan dengan nyeri persalinan kala I ( $\mathrm{p}=0.260$ ). Hasil penelitian ini tidak sesuai dengan penelitian Afritayeni (2016) di wilayah Pekanbaru yang menunjukkan ada hubungan yang signifikan antara usia ibu dengan nyeri persalinan kala I di Pekanbaru $(\mathrm{p}=0,001)$. Hal tersebut dimungkinkan karena data yang diperoleh selama penelitian menunjukkan variasi yang rendah (tidak heterogen) berdasarkan kelompok umur dimana dari 32 responden hanya ada 2 ibu bersalin yang berumur $>35$ tahun dan jumlah sampel yang relatif tidak banyak.

Faktor paritas juga tidak terbukti berhubungan dengan dengan nyeri persalinan kala $I(p=0,706)$. Hasil penelitian ini tidak sejalan dengan penelitian Afritayeni (2016) di Wilayah Pekanbaru yang menunjukkan ada hubungan yang signifikan antara paritas ibu dengan nyeri persalinan kala I di Pekanbaru $(\mathrm{p}=0,000)$. Perbedaan hasil penelitian dimungkinkan karena data yang diperoleh selama penelitian menunjukkan lebih banyak responden primigravida $(62,5 \%)$ dibandingkan multigravida (37,5\%). Ibu bersalin yang telah memiliki pengalaman melahirkan sebelumnya telah memiliki pengalaman mengatasi nyeri pada persalinan sebelumnya (Rejeki, 2014). Selain itu, kemungkinan karena faktor jumlah sampel yang relatif tidak banyak dan ada faktor-faktor lain yang tidak dimasukkan dalam analisis pada penelitian ini. Keterbatasan penelitian ini hanya memasukkan tiga variabel, yaitu kecemasan, usia dan kecemasan untuk membuktikan faktor-faktor yang berhubungan dengan nyeri persalinan. Perlunya penelitian yang akan datang memasukkan multifaktor yang berpengaruh terhadap kejadian nyeri persalinan dengan mengendalikan faktor-faktor luar (confounding) melalui analisis multivariat.

\section{Referensi}

Adam, J. \& Umboh, J. M. L. (2015). Hubungan antara umur, paritas dan pendampigan suami dengan intensitas nyeri persalinana kala I fase aktif deselerasi di ruang bersalin RSUD Prof. Dr. H. Aloei Saboe Kota Gorontalo. JIKMU. 5 (4). 406-413. 2015. Retreived from: https://ejournal.unsrat.ac.id/index.php/jikmu/article/view/7464/7132

Afritayeni (2017). Hubungan umur, paritasdan pendamping persalinan dengan intensitas nyeri persalinan kala I, Journal Endurance. 2 (2). 178-185. 2017. DOI: https://doi.org/22216/Jen.V212.1852

Agustina, R., Hartati \& Sumarni. (2016). Analisis hubungan tingkat kecemasan dan nyeri persalinan kala I primipara di wilayah kerja puskesmas kota pekalongan. Jurnal Litbang kota Pekalongan. 10 (2). 2016. Retreived from: https://jurnal.pekalongankota.go.id/index.php/litbang/article/view/43

Baesdo, K. (2009). Association between generalized anxiety levels and pain in a community sample:evidence for diagnostic specificity. Journal of Anxiety Disorders. (14) February 2009. DOI: https://doi.org/10.1016/J.Jenydis.2009.02.007

Bandiyah, S. (2009). Kehamilan, persalinan dan gangguan kehamilan . Yogyakarta: Nuha Medika

Bobak, I. M., Jensen, M. D., Lowdermilk, D. L. (2012). Buku Ajar Keperawatan Maternitas. Ed.4. Jakarta: EGC Chapman, V. (2006). Asuhan kebidanan persalinan dan kelahiran. Jakarta: EGC

Indrayani \& Djami, M. (2016). Update asuhan persalinan Dan Bayi Baru Lahir. Jakarta: CV Trans Info Media

Indrayani, D. (2013). Asuhan persalinan dan bayi baru lahir. Jakarta: Trans Info Media.

Judha, M., \& Sudarti, F. A. (2012). Teori pengukuran nyeri dan nyeri persalinan. Yogyakarta: Nuha Medika

Kaplan, H. I. (2010). Ilmu kedokteran jiwa darurat. Jakarta: Widya Medika 
Keliat, B. A. (2011). Manajemen keperawatan psikososial dan kader kesehatan jiwa. Jakarta: EGC.

Notoatmodjo, S. ( 2016). Metodologi penelitian kesehatan. Jakarta: Rineka Cipta

Potter, P. A., \& Perry, A. G. (2005). Fundamental keperawatan konsep, proses, dan praktek. Jakarta: EGC

Rejeki, S., Ulfa, N., \& Kristanti, R. N., Retno. (2013). Tingkat nyeri pinggang kala I persalinan melalui teknik back effleurage dan counter pressure. Jurnal Keperawatan Maternitas. 1 (2). 2013. Retreived from: https://jurnal.unimus.ac.id/index.php/JKMat/article/view/999

Sariati, Y. (2016). Pengaruh Hypnobirthing terhadap Tingkat Kecemasan Ibu Bersalin dan Lama Persalinan. Jurnal Ilmiah Bidan. 1(3), 35-44. Retreived from: https://www.neliti.com/id/publications/227213/pengaruh-hypnobirthing-terhadap-tingkat-kecemasanibu-bersalin-dan-lama-persalin

Sondakh, J. J. (2013). Asuhan kebidanan persalinan dan bayi baru lahir. Jakarta: Erlangga.

Sumarah, Widyastuti, Y. A., \& Wiyati, N. (2012). Perawatan ibu bersalin. Yogyakarta: Fitramaya

Syalfina, A. D. (2017). Faktor resiko dan penanganan nyeri persalinan. Jurnal Hospital Mojopahit. 9 (2). (78-89). 2017. DOI: https://doi.org/10.5281/Zenodo.3514550

Wildan, M., \& Purwaningrum, Y. (2013). Pengaruh teknik relaksasi terhadap adaptasi nyeri persalinan ibu bersalinkala I fase aktif di BPS wilayah Puskesmas Patrang kabupaten Jember tahun 2012. Jurnal Ilmu Kesehatan Masyarakat. 9(1). 57-65. $\quad$ Retreived https://jurnal.unej.ac.id/index.php/IKESMA/article/view/1098

Yuliatun, L. (2008). Penanganan nyeri persalinan dengan metode nonfarmakologi. Malang: Bayumedia 